\title{
Pattern of Ophthalmological Diseases in the Patients of Shree Birendra Hospital
}

\author{
Rajkarnikar $S^{1}$, G urung $A^{2}$, B ist $\mathbf{R R}^{3}$ Shrestha $\mathbf{R}^{4}$, Shrestha $S M^{5}$ \\ ${ }^{1}$ Dr Sagar R ajkarnikar, Ophthalmologist, ${ }^{2} \mathrm{Dr}$ Anu G urung, O phthalmologist and Head of the Department, ${ }^{3} \mathrm{Dr}$ Ramesh \\ $\mathrm{R}$ aj Bist, S enior Consultant Ophthalmologist, ${ }^{4} \mathrm{Dr}$ Ram Shrestha, O phthalmologist, Department of O phthalmology, Shree \\ Birendra Hospital, C hhauni, ${ }^{5}$ Mr Susan Man Shrestha, Statistician, Mother and Infant Research Activities
}

\begin{abstract}
Introduction: Blindness is one of the most tragic yet often avoidable disabilities in the developing world. The pattern of ocular diseases varies in different parts of Nepal due to differences in socioeconomic and geographic factors. This retrospective study likely reflects the pattern of ocular diseases in Kathmandu Valley.
\end{abstract}

Aim: To assess the patterns of ocular disease in the patients attending the outpatient department of Ophthalmology from 14th April 2009 to 13th April 2010 at the Army Hospital.

Methods: This is a retrospective study and all the new cases which attended the department of Ophthalmology of Shree Birendra Hospital in the year 2066 were included. The diseases were divided into 11 groups i.e. lid \& adenexal disorder, disease of conjunctiva \& sclera, corneal diseases, lens associated disorders, diseases of uveal tract, refractive error, glaucoma \& its associations, posterior segment diseases, ocular \& systemic neoplastic disorders, Nekebadi (annual medical check up) and others.

Result: The total number of patients recorded in the department of O phthalmology is 16709. Among them 4473 were regular serving army personnel and 12236 were ex-army and army families.

Conclusion: The pattern of eye disease varies in different age groups. In younger age group conjunctival, scleral disease and refractive error were commonly seen whereas in elder age group lens disorder was frequently seen. The number of blind patients was more in females than in male patients.

Key words: Conjunctivitis, Cataract, Blindness.

\section{Introduction}

Blindness is one of the most tragic yet often avoidable disabilities in the developing world ${ }^{1}$. The pattern of Eye diseases vary in different parts of Nepal due to differences in socioeconomic and geographic factors. The army hospital in Kathmandu not only treats army personnel but also their family and ex- servicemen who comprise almost $60 \%$ of the population. This retrospective study is helpful for the study of pattern of ocular diseases among army personnel and their families.

\section{Aim}

To study and assess the different patterns of ocular diseases in the patients attending the outpatient department from 14th A pril 2009 to 13th A pril 2010 in the Army Hospital.

\section{Methods}

This is a retrospective study and all the new cases which were diagnosed in the department of Ophthalmology, Shree Birendra Hospital from 14th April 2009 to 13th April 2010 were included. In this study the patients were divided into army personnel, their families and ex-army. The ocular diseases were divided into different 11 groups. Data was tabulated and interpreted in terms of percentage using SPSS version 18.0.

\section{Results}

The total number of cases recorded was 16709 . Among them 4473 were serving army personnel and 12236 were ex-army and army families.

In total 16709 patients there are 29923 cases. Some patients have one problem in one eye and some had more than one problem in one or both eyes.

Among the patients, the youngest patient is of 18 days and eldest is of 96 year with mean age 46.59 years. The percentage of male and female is $41.51 / 58.48 \%$ (i.e. 5080 and 7156). Among the number of serving army personnel, male (4101) is more than female (372) and in total patients, male/ female is $9181 / 7528$ (i.e. 54.9 : $45.1 \%)$.

The patients are divided into 11 different groups according to ocular diseases. Group I (Lid \& Adenexa): Chalazion, Stye, Blepharitis, Acute/ Chronic Dacryocystitis, Dacryoadenitis, Entropion, Ectropion, Congenital Dacryocystitis, post/ failed DCR Surgery, Ethmoidocele, Ptosis, Pre-septal Cellulitis, Cellulitis, Caranculitis, Trichiasis, Lid Edema, Epiphora, Concretion, Meibominitis, Wart, Canthal Cyst etc. 
Group II (Conjunctiva \& Sclera): Conjunctivitis, Trachoma, Pinguecula, Pterygium, Episcleritis, Scleritis, Sub Conjunctival Haemorrhage, Dry Eye, Conjunctival Cyst/ Naevus/ Melanoma etc.

Group III (Cornea): Keratitis, laceration, dystrophies, degeneration, opacity, ulcer, foreign body, Microcornea, Bullous Keratopathy, Penetrating Keratoplasty etc.

Group IV (Lens): Cataract, Pseudophakia, Aphakia, Subluxated Lens, Posterior Capsular Opacification etc.

Group V (Uveal Tract): Uveitis, Endophthalmitis, panophthalmitis etc.

Group VI: Refractive errors, presbyopia, asthenopia, amblyopia, headache etc.

Group VII (Posterior Segment): Retinopathies, macular diseases, optic nerve lesions, vitreous lesions, retinal/ choroidal detachment etc.

Group VIII (Glaucoma): Primary and secondary glaucoma, glaucoma suspect etc.

Group IX (Tumours): consists of any neoplasm effecting eye include Ca Maxilla, melanoma, cerebro-pontine angle tumor, glioma, angioma etc.

Group X (Others): Systemic diseases affecting eye (HTN, DM, Thyroid Disease, Henson's Disease, Chicken Pox, Meningitis, Myasthenia Gravis, Seizure Disorder, Gilbert syndrome, Aplastic Anemia, Hepatitis, Vertigo, Xanthelesma, Amarousis Fugax, Urethritis,), Proptosis, Artificial Eye, Anophthalmos, Contracted Socket, Atrophic/ Phthisis Bulbi, Diplopia, Post Lightening, Retrobulbar Neuritis, Trauma, Squint, Computer Vision Syndrome, Cranial Nerve Palsies $\left(3^{\text {rd }}, 4^{\text {th }}, 5^{\text {th }}, 6^{\text {th }}, 7^{\text {th }}\right)$ etc.

Group XI: Nekebadi (Annual Medical Check Up) of army personnel.

The number and percentages of the eye diseases are given in Table 1. 
Tab 1. Visual Acuity and Diagnosis

\begin{tabular}{|c|c|c|c|c|c|c|c|c|c|c|c|c|c|c|c|c|}
\hline \multirow{3}{*}{\multicolumn{2}{|c|}{ ॠँّ }} & $\begin{array}{c}\text { Percentage of Total } \\
\text { Cases }\end{array}$ & $\begin{array}{l}\infty \\
@ \\
0\end{array}$ & $\begin{array}{l}\text { Jे } \\
\text { மீं }\end{array}$ & 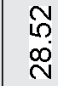 & & 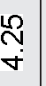 & $\begin{array}{l}\hat{O} \\
\stackrel{\circ}{N}\end{array}$ & $\frac{9}{0}$ & $\begin{array}{l}\infty \\
\infty \\
\infty \\
\infty\end{array}$ & סे & 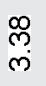 & 于े & 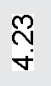 & $\stackrel{\infty}{\circ}$ & 움 \\
\hline & & $\begin{array}{l}\text { Disease-wise } \\
\text { Percentage }\end{array}$ & $\stackrel{\bullet}{\circ}$ & in & $\stackrel{0}{N}$ & & $\check{+}$ & ì & $\hat{\circ}$ & $\stackrel{\infty}{\sim}$ & $\stackrel{\infty}{i}$ & $\stackrel{N}{m}$ & $\stackrel{+}{\circ}$ & $\stackrel{\circ}{\forall}$ & $\stackrel{\text { m) }}{m}$ & 용 \\
\hline & & No. of cases & ণ্ণ & $\stackrel{Q}{N}$ & 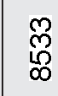 & & $\stackrel{m}{N}$ & 尺̊ & $\stackrel{\mathscr{N}}{N}$ & $\begin{array}{l}8 \\
\stackrel{0}{10} \\
\text { Ln }\end{array}$ & চ্் & $\frac{}{5}$ & $\stackrel{\text { Y }}{\text { T }}$ & 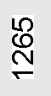 & $\underset{ָ}{\stackrel{N}{N}}$ & ֶָ \\
\hline \multicolumn{3}{|c|}{ Percentage of total blind cases } & & $m$ & $\stackrel{\circ}{\circ}$ & & $\stackrel{1}{0}$ & $\frac{m}{\frac{8}{4}}$ & $\stackrel{\infty}{\circ}$ & L & $\stackrel{\sim}{6}$ & $\ddot{m}$ & $\hat{0}$ & $\stackrel{\infty}{N}$ & & 옹 \\
\hline \multirow{3}{*}{$\stackrel{\text {. }}{\bar{m}}$} & \multirow{3}{*}{ 扈 } & $\begin{array}{c}\text { Percentage of Total } \\
\text { Cases }\end{array}$ & & $\begin{array}{l}\text { g } \\
\text { ப. }\end{array}$ & $\stackrel{N}{N}$ & & $\begin{array}{l}8 \\
0 \\
0\end{array}$ & ๙̃. & $\frac{\circ}{0}$ & $\stackrel{8}{\bullet}$ & $\begin{array}{l}\frac{R}{R} \\
0\end{array}$ & P̊ & $\stackrel{0}{\circ}$ & $\begin{array}{l}\text { Jे } \\
0 \\
0\end{array}$ & & \& \\
\hline & & $\begin{array}{l}\text { Disease-wise } \\
\text { Percentage }\end{array}$ & & $\stackrel{N}{\mathscr{\theta}}$ & $\stackrel{9}{N}$ & & $\begin{array}{l}\infty \\
\infty \\
\infty\end{array}$ & $\stackrel{\infty}{\infty}$ & $\stackrel{N}{\sim}$ & $\stackrel{n}{m}$ & $\stackrel{\infty}{\stackrel{\sim}{d}}$ & $\stackrel{F}{E}$ & $\stackrel{\varphi}{\sim}$ & Ñ & & $\stackrel{\sigma}{=}$ \\
\hline & & No. of cases & & $\hat{\mathscr{N}}$ & $\begin{array}{c}\infty \\
\mathscr{0}\end{array}$ & & 워 & $\frac{N}{N}$ & প & $\stackrel{\mathscr{O}}{\leftarrow}$ & $\stackrel{\searrow}{\Sigma}$ & $\stackrel{9}{\mp}$ & $\stackrel{W}{\sim}$ & $\bar{\infty}$ & & స్ \\
\hline \multirow{3}{*}{\multicolumn{2}{|c|}{ 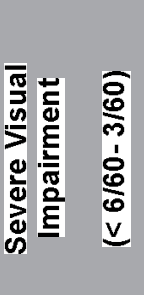 }} & $\begin{array}{c}\text { Percentage of Total } \\
\text { Cases }\end{array}$ & & $\stackrel{+}{0}$ & $\stackrel{\circ}{\circ}$ & & $\bar{\sigma}$ & 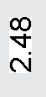 & 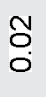 & 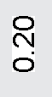 & $\stackrel{\infty}{\circ}$ & $\stackrel{9}{\circ}$ & $\stackrel{8}{\circ}$ & Б் & & 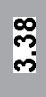 \\
\hline & & $\begin{array}{l}\text { Disease-wise } \\
\text { Percentage }\end{array}$ & & $\hat{0}$ & $\stackrel{\bullet}{\circ}$ & & ن & ণे & $\stackrel{\text { i }}{\mathrm{N}}$ & $\stackrel{\circ}{-}$ & $\stackrel{\infty}{\infty}$ & $\cong$ & $\stackrel{\circ}{\circ}$ & $\stackrel{10}{\mathrm{~N}}$ & & m \\
\hline & & No. of cases & & $\stackrel{m}{=}$ & $\mathscr{\ell}$ & & $m$ & 过 & $\Lambda$ & ฉึ & חొ & $\stackrel{\infty}{\sim}$ & 0 & ๗ & & $\frac{N}{0}$ \\
\hline \multirow{3}{*}{ 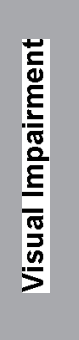 } & \multirow{3}{*}{$\begin{array}{l}\delta \\
0 \\
0 \\
1 \\
\frac{1}{0} \\
v \\
v\end{array}$} & $\begin{array}{c}\text { Percentage of Total } \\
\text { Cases }\end{array}$ & & 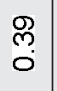 & $\stackrel{R}{r}$ & & 量 & 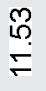 & $\stackrel{\square}{\circ}$ & $\stackrel{\mathscr{O}}{-}$ & $\begin{array}{l}8 \\
\infty \\
0\end{array}$ & $\frac{\infty}{\dot{0}}$ & 옹 & $\begin{array}{c} \\
\infty \\
0\end{array}$ & $\frac{⿱}{0}$ & స్ \\
\hline & & $\begin{array}{l}\text { Disease-wise } \\
\text { Percentage }\end{array}$ & & $\begin{array}{l}\varphi \\
\dot{0}\end{array}$ & $\stackrel{\sim}{0}$ & & 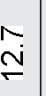 & $\underset{v}{\stackrel{V}{J}}$ & $\stackrel{\nabla}{\sim}$ & $\stackrel{10}{\circ}$ & $\stackrel{\forall}{\mathscr{N}}$ & in & $\stackrel{\circ}{\stackrel{+}{ \pm}}$ & $\stackrel{N}{\sim}$ & $\ddot{m}$ & $\stackrel{?}{\infty}$ \\
\hline & & No. of cases & & $\stackrel{\infty}{\mp}$ & $\stackrel{\mathscr{ల}}{\mathscr{N}}$ & & 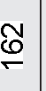 & 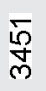 & ले & 冓 & $\stackrel{\infty}{\sim}$ & 负 & 오 & $\stackrel{J}{\text { J }}$ & テ & § \\
\hline \multirow{4}{*}{ 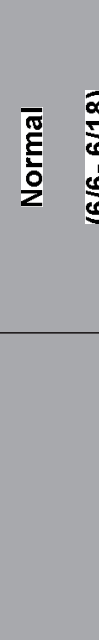 } & \multirow{3}{*}{$\begin{array}{l}\frac{\infty}{\omega} \\
0 \\
0 \\
0\end{array}$} & $\begin{array}{c}\text { Percentage of Total } \\
\text { Cases }\end{array}$ & $\begin{array}{l}\infty \\
@ \\
0\end{array}$ & $\stackrel{\sim}{\forall}$ & $\stackrel{\mathscr{L}}{\sim}$ & & $\begin{array}{l}\tilde{O} \\
0 \\
0\end{array}$ & $\stackrel{9}{\circ}$ & 萬 & $\frac{n}{\circ}$ & ర్ & 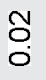 & 옹 & $\stackrel{\substack{0 \\
\circ}}{\circ}$ & $\stackrel{8}{0}$ & $\stackrel{3}{6}$ \\
\hline & & $\begin{array}{l}\text { Disease-wise } \\
\text { Percentage }\end{array}$ & 8 & 芦 & $\begin{array}{l}m \\
\infty \\
\infty \\
\infty\end{array}$ & & $\begin{array}{l}m \\
m \\
\infty \\
0\end{array}$ & $\stackrel{\widehat{N}}{\grave{N}}$ & $\begin{array}{l}\circ \\
\stackrel{0}{0}\end{array}$ & $\begin{array}{l}\circ \\
\stackrel{\circ}{\infty} \\
\infty\end{array}$ & $\underset{\sim}{\stackrel{\leftrightarrow}{\sim}}$ & $\frac{\ulcorner}{\infty}$ & $\stackrel{v}{\dot{v}}$ & $\begin{array}{l}m \\
\infty \\
\infty \\
\infty\end{array}$ & $\begin{array}{l}\mathscr{6} \\
\mathscr{8}\end{array}$ & $\stackrel{m}{0}$ \\
\hline & & No. of cases & ষ্ণ & $\underset{\underset{\sim}{\sim}}{\stackrel{\infty}{\sim}}$ & 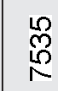 & & $\begin{array}{l}\text { P } \\
\infty\end{array}$ & 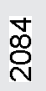 & $\dddot{\varrho}$ & $\stackrel{\substack{N \\
⿱}}{\forall}$ & 吕 & ণ্ণ & N & $\stackrel{\infty}{N}$ & $\stackrel{\infty}{\stackrel{\infty}{\leftarrow}}$ & 용 \\
\hline & & $\begin{array}{l}\frac{n}{n} \\
\frac{0}{0} \\
\frac{\pi}{0} \\
\frac{\pi}{0}\end{array}$ & $\begin{array}{l}\bar{\pi} \\
\frac{\text { हn் }}{2}\end{array}$ & $\begin{array}{l}\mathbb{\pi} \\
\frac{x}{0} \\
\frac{0}{0} \\
\frac{0}{0} \\
\infty \\
.0\end{array}$ & 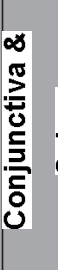 & $\frac{\pi}{0}$ & 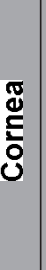 & ๕ับ & 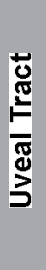 & 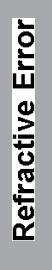 & 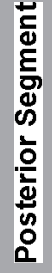 & $\begin{array}{l}\frac{\pi}{8} \\
\frac{0}{0} \\
\frac{\pi}{0}\end{array}$ & $\stackrel{\frac{n}{2}}{\frac{2}{E}}$ & 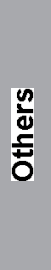 & $\begin{array}{l}\frac{\overline{0}}{\pi} \\
\frac{0}{2} \\
\frac{0}{2}\end{array}$ & 范 \\
\hline
\end{tabular}


According to $\mathrm{WHO}$, classification of vision is describes as follow, Normal Vision: 6/6-6/18, Visual Impairment: < 6/18- 6/60, Severe Visual Impairment: < 6/60 - 3/60 and Blind: < 3/60. Among 29923 cases, total blind cases are 3562, the maximum number of blind cases (1472) is due to lens and its disorders which account $18.8 \%$ of lens problem and $4.9 \%$ among the total cases that attended in OPD and $41.3 \%$ of whole blind cases. Similarly $18.8 \%(240)$ of corneal disorder cases are blind i.e. $6.7 \%$ of whole blind cases and $0.8 \%$ cases are blind due to corneal disorder. Blindness due to posterior segment and glaucoma accounts for $0.7 \& 0.3 \%(224 \& 119)$ respectively.

Tab 2. Diagnosis and Age Group

\begin{tabular}{|c|c|c|c|c|c|}
\hline Diagnosis & $0-14$ Yrs (\%) & $15-40$ Yrs (\%) & $41-60$ Yrs (\%) & $>60$ Yrs $(\%)$ & Total (\%) \\
\hline Normal & $30(2.0)$ & $120(2.1)$ & $45(1.2)$ & $9(0.2)$ & $204(1.3)$ \\
\hline Lid \& Adenexa & $185(12.5)$ & $480(8.5)$ & $159(4.3)$ & $134(3.2)$ & $958(6.4)$ \\
\hline Conjunctiva \& Sclera & $585(39.7)$ & $1560(27.9)$ & $943(25.6)$ & $425(10.4)$ & $3515(23.7)$ \\
\hline Cornea & $46(3.1)$ & $474(8.4)$ & $172(4.6)$ & $110(2.6)$ & $802(5.4)$ \\
\hline Lens & $22(1.4)$ & $170(3.0)$ & $918(24.9)$ & $2693(66.0)$ & $3803(25.6)$ \\
\hline Uveal Tract & $8(0.5)$ & $71(1.2)$ & $22(0.5)$ & $23(0.5)$ & $124(0.8)$ \\
\hline Refractive Error & $541(36.8)$ & $1281(22.9)$ & $752(20.4)$ & $222(5.4)$ & $2796(18.8)$ \\
\hline Posterior Segment & $8(0.5)$ & $149(2.6)$ & $113(3.0)$ & $175(4.2)$ & 445 (1.4) \\
\hline Glaucoma & $2(0.1)$ & $78(1.3)$ & $59(1.6)$ & $71(1.7)$ & $210(1.4)$ \\
\hline Tumors & $3(0.2)$ & $4(0.2)$ & $8(0.2)$ & $9(0.2)$ & $24(0.1)$ \\
\hline Others & $30(2.0)$ & $275(4.9)$ & $176(4.7)$ & $207(5.0)$ & $698(4.7)$ \\
\hline Nekebadi & & $910(16.3)$ & $311(8.4)$ & & $1221(8.2)$ \\
\hline Total & $1470(9.9)$ & $5582(37.6)$ & $3678(24.8)$ & $4078(27.5)$ & $14808(100.0)$ \\
\hline
\end{tabular}

Table 2 shows the diagnosis and age group of patients. In all age group, except $>60$ years, the most common ocular disease is conjunctival \& scleral disorders $3515(23.7 \%)$ followed by refractive error $2796(18.8 \%)$. In the group >60 years, the maximum no. of patients are of lens disorder $2693(66 \%)$ and $2^{\text {nd }}$ most common disease is conjunctiva $\&$ scleral problem $425(10.4 \%)$ followed by refractive error $222(5.4 \%)$, others $207(5.0 \%)$ and posterior segment problem accounts 175 (4.2\%).

In age group 41-60 yrs, $2^{\text {nd }}$ most common disease is lens disorder 918 (24.9\%) followed by refractive error 752 (20.4\%). Similarly in age group $15-40$ yrs $\& 0-14$ yrs also conjunctival $\&$ scleral disorder is the most common problem $1560 \& 585(27.9 \& 39.7 \%)$ respectively. In these group second most common problem is refractive error $1281 \& 541$ $(22.9 \& 36.8 \%)$. 
Tab 3. Age and Visual Acuity

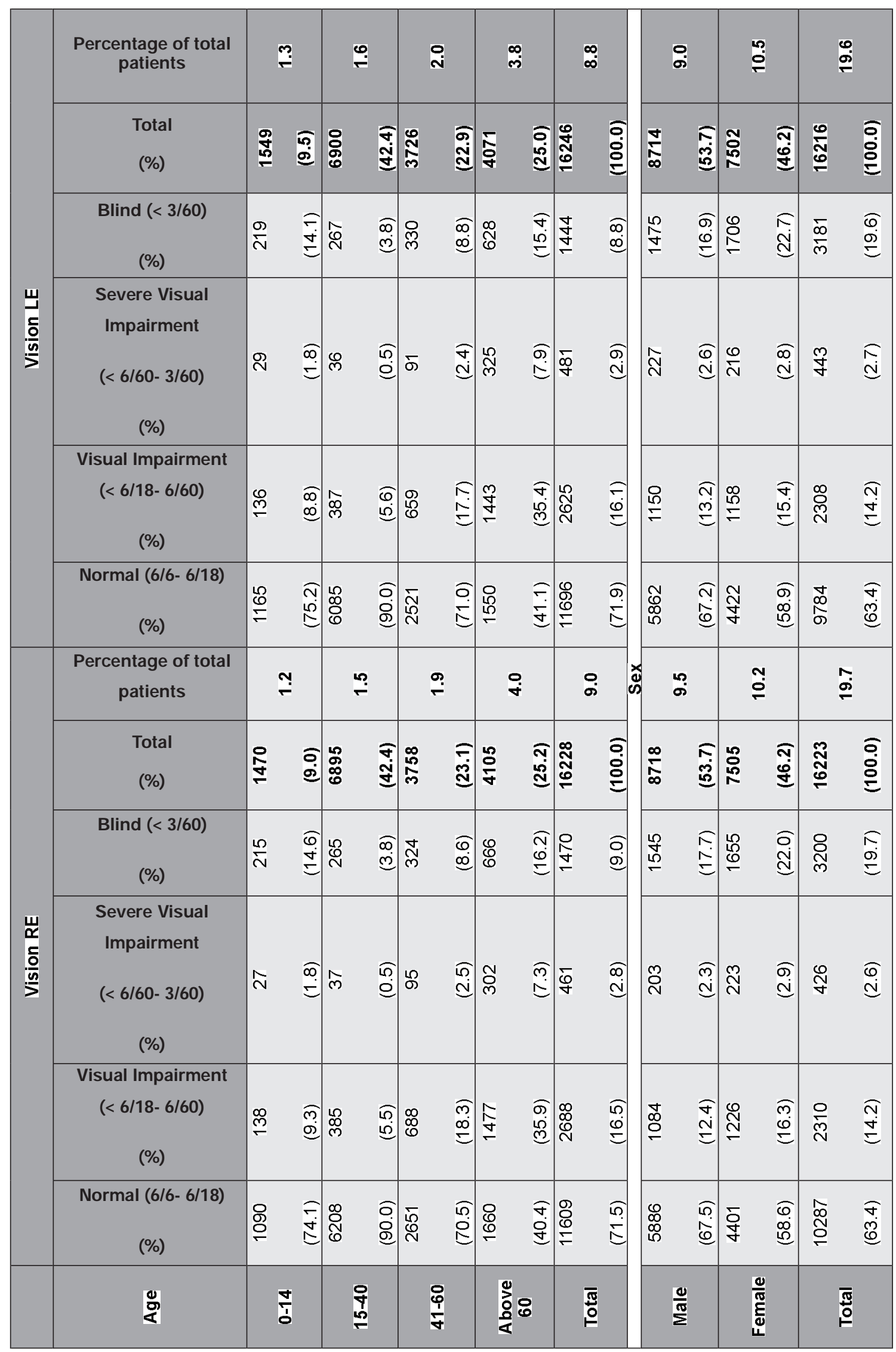


Table 3 shows the age, sex and visual acuity of patients. In the age group 0-14 yrs, $72.3 \%$ had normal vision, $9.8 \%$ had visual impairment (VI), 2.0\% had severe visual impairment (SVI) and $15.6 \%$ were blind. In 15-40 yr age group 5.0\% were blind. Similarly $10.7 \& 20.0 \%$ patients were blind in $41-60$ yrs $\&>60$ yrs respectively.

The percentage of blind patient is the highest in the eldest age group ( $>60 \mathrm{yrs}$ ) i.e. $4.2 \%$ of whole attending OPD patients. Among the age group 41-60 yrs about 2\% patients are blind and that of age group $15-40$ yrs is $1.6 \%$ and in youngest group is $1.25 \%$ of whole attending OPD patients.

$53.8 \%$ patients were male and $46.05 \%$ were female patients. Among male patients $17.8 \%$ were blind, $2.45 \%$ had SVI, $13.1 \%$ had VI and $66.4 \%$ had normal vision. Similarly among females, $57.35 \%$ had normal vision, $16.35 \%$ had VI, $2.9 \%$ had SVI and $23.15 \%$ were blind. Thus this OPD data showed there is larger number of blind patients in female than male.

Tab 4. Nekebadi

\begin{tabular}{|l|c|c|}
\hline \multicolumn{1}{|c|}{ Diseases } & Number & Percent \\
\hline Normal & 1025 & $83.9 \%$ \\
\hline Lid \& Adenexa & 5 & $0.4 \%$ \\
\hline Conjunctiva \& Sclera & 99 & $8.1 \%$ \\
\hline Cornea & 5 & $0.4 \%$ \\
\hline Refractive Error & 78 & $6.4 \%$ \\
\hline Glaucoma & 7 & $0.6 \%$ \\
\hline Others & 2 & $0.2 \%$ \\
\hline Total & $\mathbf{1 2 2 1}$ & $\mathbf{1 0 0 . 0 \%}$ \\
\hline
\end{tabular}

Table 4 shows the number of regular army personnel who attended OPD for Nekebadi (routine medical check up). Among 1221, 1025 (83.9\%) were normal but rest $196(16.1 \%)$ had different problems. Among these 8.1\% (99) had conjunctival \& scleral problem, $6.4 \%$ (78) refractive errors, $0.6 \%$ (7) glaucoma, $0.4 \%$ (5) cases with lid \& adenexal and corneal problem. $0.2 \%(2)$ had other problems.

\section{Discussion}

In 1988, the world population was approximately 5.1 billion. Over the last 20 years, it has increased by approximately $30 \%$, reaching 6.7 billion in 2008. During the same period, the world population has also become proportionally older, as the number of people aged 65 years and over has increased by approximately $55 \%$, from 320 million in 1988 to 500 million in 2008. Since the prevalence of visual impairment becomes higher as people age, this combination of an increasing population and an ageing population is expected to cause a significant increase in the total number of blind people ${ }^{2}$. In 1988, the number of people who were blind was estimated to be 37 million worldwide. By 2002-04, the latest period for which, it was estimated to be 45 million: 8 million blind due to uncorrected refractive error and 37 million blind due to other causes. ${ }^{3,4}$ It is thought that at least $60 \%$ of blind people are women ${ }^{2,5,6,7}$.

Globally, based on the 2002 world population, more than 161 million people were visually impaired, of whom 124 million had low vision and 37 million were blind, including 1.4 million under the age of 15 years. ${ }^{8}$

Using the World Health Organization (WHO) definition of blindness as a visual acuity of $3 / 60$ or less, it is estimated that currently there are 45 million individuals worldwide who are bilaterally blind and another 135 million that have severely impaired vision in both eyes. The fact that there are 180 million people in the world today who are in some way severely visually disabled is a tragic, unacceptable situation in both social and economic terms, but this number does not even begin to address the additional hundreds of millions who are disabled by monocular visual loss ${ }^{9}$.
According to the World Health Organization worldwide there are an estimated 45 million people that are blind with an additional 135 million individuals visually impaired. ${ }^{10}$ Globally it is known that cataract is the leading cause of blindness, with some 16-20 million people suffering from blinding cataract.11,12 In country specific terms, India is the country with the highest number of blind people (over 9 million) with the most prevalent cause of blindness and low vision being unoperated cataract, as indicated by several population based studies over the past two decades. ${ }^{13-15}$

In many parts of the country, lack of awareness and ignorance about any eye disease is still widespread where people take it as a curse of god or sin of previous birth, and very often, they turn to local shamans and spiritual healers for cure in such a situation instead of getting timely medical treatment in the hospita ${ }^{17}$.

\section{Causes of blindness}

Over the last twenty years, the causes of blindness have changed in proportion and actual number. Cataract has remained the major cause of blindness globally. It is particularly important in Asia. The numbers of people blinded by trachoma, onchocerciasis, and vitamin A deficiency have tended to decrease over the last twenty years ${ }^{18}$.

In our study, the major cause of blindness is due to lens and its disorder which accounts $41.3 \%$ of whole blind cases. Second major cause of blindness is due to conjunctiva and scleral disorder (19.0\%), then lid and adexenal disorder $(8.3 \%)$ followed by others $(7.8 \%)$, corneal cause $(6.7 \%)$ and posterior segment disorder $(6.2 \%)$ are the cause of blindness in our study. 
In worldwide the major cause of blindness is cataract ${ }^{5,9,17-20}$. Besides cataract the cause of blindness vary in different parts of world. The two most common causes of blindness in Asian studies are cataract and under corrected refractive errors. This contrasts with Western populations, in which the leading cause of blindness (accounting for more than $50 \%$ of cases) is age related macular degeneration (AMD) in white people, and cataract and glaucoma in black people However, in Singapore and Mongolia, glaucoma was the principal cause of both unilateral and bilateral blindness while in the Shihpai Eye Study in Taiwan, retinal diseases as a group, including AMD and myopic degeneration, were the leading cause There is an increasing body of epidemiological data on the major age related eye diseases in Asian populations. The epidemiology of glaucoma and refractive errors, in particular appears to be well characterized. In contrast, there remains paucity of well conducted population based studies on the prevalence of DR and AMD in Asia ${ }^{7,8,18}$.

Cataract causes $41.8 \%$ of global blindness (15 829000 persons), operable/curable cataract being the probable cause of the vast majority ${ }^{7}$. Senile cataract and anterior segment eye infection were the two eye diseases most frequently seen in Giwa community. The results of this study showed that preventable and curable eye diseases were most common ${ }^{19}$.

In recent years the epidemiology of blindness has changed, shifting away from traditional infectious causes, such as trachoma, onchocerciasis, and leprosy, to other important causes, such as cataract. Indeed, so much emphasis has been placed on managing the backlog of cataract surgery in many developing countries that programmes dealing with other causes of blindness have in some cases been neglected ${ }^{9}$.

\section{Ocular disease and Age group}

In our study, the most frequent ocular disease is conjunctival and scleral disorder in all age groups except the eldest age group, followed by refractive error. However, an increasing number of people are at risk of visual impairment as populations grow and people live longer. Developing countries are already aging much faster than those in the developed world. In 2000 more than 248 million (59\%), of the roughly 418 million persons aged 65 and over, lived in developing countries. By the year 2020 this is projected to rise to $67 \%$. The UN estimates that by 2020 there will be a global elderly population of 698 million ${ }^{21}$.

In the youngest age group (0-14 yrs), the most common problem is of conjunctival and scleral disease followed by refractive error, corneal disorders which were similar with other studies. ${ }^{20,22,23,29}$

Blindness prevalence surveys have been conducted in Nepal nationally and in one region of Pakistan that yielded all age blindness prevalence rates of $0.8 \%$ and $1.0 \%$ respectively. ${ }^{24,25} \mathrm{~A}$ subsequent survey in two administrative regions of Nepal identified a blindness prevalence of $3.0 \%$ in people 45 years and older ${ }^{5,26}$.

The proportion of subjects with normal vision $(\geq 6 / 12)$ was shown to decrease significantly with increasing age. The age specific blindness prevalence was found to be greater with increased age ${ }^{5}$.
In our study also as the increased age, the pattern of disease also varies. Lens disorder is seen as the most common problem in eldest age group (66\%) followed by conjunctival and scleral problem, refractive error and then posterior segment problem.

A study done in school eye health screening in Kaduna, Northern Nigeria by A.V. Kehinde et al found the commonest causes of eye disorders were allergic conjunctivitis, refractive error, and infective conjunctivitis in school studying students ${ }^{29}$.

\section{Ocular disease and Sex}

There was a marked difference in presenting visual acuity between women and men. There was a higher prevalence of blindness in women $(1.72 \%)$ than men $(1.06 \%)$ in the study conducted in Bangladeshi adults. In our study the number of female blind patients was more than that of male patients. Similar findings are seen in other studies $5,6,24,26,27,28$.

\section{Conclusion}

As we age, we should be aware of the most common eye diseases which can rob our vision. If we understand some of the symptoms, some of which seem of only minor importance on their own, we are more likely to take them seriously and act on them ${ }^{30}$.

To decrease morbidity from vision loss and blindness, public health professionals must increase public awareness about Age Related Eye Diseases; integrate and coordinate timely screening, diagnosis, and treatment to prevent or correct vision loss ${ }^{31}$.

There is a general feeling among people; Blindness is punishment of the God due to ignorance and superstition and lack of information about its pathology. Usually the blind is regarded as a helpless and unproductive human. Attention to the needs of the Blind and Partially Sighted (BPS) persons has never been a national priority in Nepal. The blind has always been neglected in all aspect of development.

Neglect of timely and proper medical cure for a sensitive body part like eye is contributing to a rise in the number of cases of blindness in Nepal ${ }^{17}$.

\section{References}

1. Resnikoff S. G lobal data on visual impairment in the year 2002: Bull World Health Organ 2004;82: 844-851.

2. Allen Foster, Clare Gilbert, Gordon J ohnson. Changing patterns in global blindness: 19882008. Community Eye Health J 2008;21(67): 37-39.

3. J Hubley and C Gilbert. Eye health promotion and the prevention of blindness in developing countries: critical issues: $\mathrm{Br} J$ Ophthalmol. 2006 March; 90(3): 279-284.

4. Resnikoff $\mathrm{S}$ et al. Global magnitude of visual impairment caused by uncorrected refractive errors in 2004: Bull World Health Organ 2008;86: 63- 70. 
5. SapkotaYD, Pokharel GP, Nirmalan PK, Dulal $S$, Maharjan IM, Prakash K. Prevalence of blindness and cataract surgery in Gandaki Zone, Nepal: Br J Ophthalmol 2006;90:411-416.

6. Dineen BP, Bourne RRA, Ali SM, Noorul Huq $D M$ and J ohnson $G$ J. P revalence and causes of blindness and visual impairment in Bangladeshi adults: results of the National B lindness and Low Vision Survey of Bangladesh: Br J Ophthalmol. 2003 J uly; 87(7): 820-828.

7. B. Thylefors. Global data on blindness: Bulletin of the World Health Organization, 1995, 73 (1): 115-121.

8. Dr Ivo Kocur. G lobal pattern of blindness changes with success in tackling infectious disease and as population ages: Bulletin of the World Health Organization. DECEMBER 2004.

9. Whitcher JP, Upadhyay MP, Srinivasan M. Corneal blindness: a global perspective. Bull World Health Organ vol.79 no.3 Genebra 2001.

10. World Health Organization. Programme for the Prevention of Blindness and Deafness. Global initiative for the elimination of avoidable blindness. Geneva: WHO, 1997:1-7.

11. Thylefors $B$, Négrel AD, Pararajasegaram $R$, Dadzie KY. Global data on blindness Bull World Health Organ 1995;73:115-21.

12. Arnold J. Global cataract blindness: the unmet challenge. Br J Ophthalmol 1998;82:593-6.

13. Limburg H, Vaidyathan K. Cataract blindness on the rise? Results of a door-to-door examination in Mohadi. Indian J Ophthalmol 1996;44:241-4.

14. Gupta SK. Prevalence and risk factors of cataract in India: a review. Dev Ophthalmol 1997;27:1-5.

15. Dandona L, Dandona R, Naduvilath TJ. Is current eye-care policy focus almost exclusively on cataract adequate to deal with blindness in India? Lancet 1998;351:1312-16.

16. Murthy GVS, Gupta S, Ellwein LB. A populationbased eye survey of older adults in a rural district of Rajasthan. I. Central vision impairment, blindness, and cataract surgery. O phthalmology 2001;108:679-85.

17. Self-reliant in eye treatment. Blind World Magazine J anuary 16,2006.

18. Allen Foster, Clare Gilbert Gordon Johnson. Changing patterns in global blindness: 19882008. Community Eye Health J 2008;21(67): 3739.
19. Wong $T$ Y, Loon SC, Saw SM. The epidemiology of age related eye diseases in Asia: $\mathrm{Br} J$ Ophthalmol 2006;90:506-511.

20. Ogwurike S, Pam V. Pattern of Eye Diseases in Kaduna State - A rural community outreach experience: Nigerian J ournal of O phthalmology ; Vol 12, No 1 (2004).

21. Ivo Kocur. Global data on visual impairment in the year 2002. Bulletin of the World Health Organization; DECEMBER 2004.

22. Ajaiyeoba Al, Isawumi MA. Prevalence and Causes of Eye Diseases amongst Students in South-Western Nigeria. Annals of African Medicine: Vol. 5, No 4; 2006: 197-203.

23. Ajaiyeoba Al, Isawumi MA. Pattern of eye diseases and visual impairment among students in southwestern Nigeria. Int Ophthalmol (2007) 27: 287-292.

24. Brilliant GE, Pokharel RP. The epidemiology of blindness in Nepal: report of the 1981 Nepal Blindness Survey. Chelsea, Michigan: The Seva Foundation, 1988.

25. Khan MA, Gulab A, Khan MD. Prevalence of blindness and low vision in North West Frontier Province of Pakistan. Pakistan J Ophthalmol 1994;10: 39-42.

26. Pokharel GP, Regmi G. Prevalence of blindness and cataract surgery in Nepal. Br J Ophthalmol 1998;82:600- 5 .

27. Dandona L, Dandona R. Is current eye-care policy focus almost exclusively on cataract adequate to deal with blindness in India? Lancet 1998; 351: 1312- 16.

28. Murthy GVS, Gupta S. A population-based eye survey of older adults in a rural district of Rajasthan. I. Central vision impairment blindness, and cataract surgery. Ophthalmology 2001;108:679-85.

29. Kehinde AV, Ogwurike SC, Eruchalu UV, Pam $\mathrm{V}$ and Samaila E. School eye health screening in Kaduna -Northern Nigeria. Nigerian journal of surgical research Vol 7, No1-2,2005: 191 - 194.

30. Hitesh $\mathrm{K}$ Patel. Leading causes of Visual Impairment and Blindness in America according to E dison Eye Surgeon. Edison, New Brunswick, Central New J ersey, August 2010.

31. Dorothy MG, Appathurai B, Barbara AL, Christopher M. Age-related Eye Diseases: An Emerging Challenge for Public Health Professionals. Prev Chronic Dis 2005 Jul, Volume 2: NO. 3: 1-6. 